\title{
Microbiota Survey of Sliced Cooked Ham During the Secondary Shelf Life
}

\author{
Gloria Spampinato ${ }^{1}$, Francesco Candeliere ${ }^{1}$, Alberto Amaretti ${ }^{1,2}$, Fabio Licciardello ${ }^{1,2}$, \\ Maddalena Rossi ${ }^{1,2}$ and Stefano Raimondi ${ }^{1 *}$ \\ ${ }^{1}$ Department of Life Sciences, University of Modena and Reggio Emilia, Modena, Italy, ${ }^{2}$ BIOGEST-SITEIA, University \\ of Modena and Reggio Emilia, Modena, Italy
}

\section{OPEN ACCESS}

Edited by:

Laurent Dufossé,

Université de la Réunion, France

Reviewed by:

Giulia Tabanelli,

University of Bologna, Italy

loanna Mantzourani,

Democritus University of Thrace,

Greece

*Correspondence:

Stefano Raimond

stefano.raimondi@unimore.it

Specialty section:

This article was submitted to

Food Microbiology,

a section of the journal

Frontiers in Microbiology

Received: 23 December 2021

Accepted: 25 January 2022

Published: 08 March 2022

Citation:

Spampinato G, Candeliere F, Amaretti A, Licciardello F, Rossi M and Raimondi S (2022) Microbiota Survey of Sliced Cooked Ham During

the Secondary Shelf Life.

Front. Microbiol. 13:842390. doi: 10.3389/fmicb.2022.842390
Sliced cooked ham packaged in a modified atmosphere is a popular ready-to-eat product, subjected to abundant microbial contamination throughout its shelf life that can lead to deterioration of both sensorial properties and safety. In this study, the microbial load and the chemical-physical features of cooked ham of five producers were monitored for a period of 12 days after the opening of the packages (i.e., the secondary shelf life), during which the products were stored in a domestic refrigerator at $5.2 \pm 0.6^{\circ} \mathrm{C}$. The sensorial properties presented a perceivable decay after 8 days and became unacceptable after 12 days. High-performance liquid chromatography analysis and solid-phase microextraction coupled with gas chromatography profiling of volatile metabolites indicated that lactic acid, ethanol, acetic acid, acetoin, 3methyl-1-butanol, and 2-3 butanediol were the main metabolites that characterized the evolution of the analyzed cooked ham. The microbiota was monitored by 165 ribosomal RNA gene profiling and culture-dependent techniques. Already at the opening of packages, all the products presented high microbial load, generally dominated by lactic acid bacteria, with evident differences among the products. The increase of lactic acid bacteria somehow protected samples from abundant contamination by other bacteria, concurring with the evolution of more safe products. This role was exerted by numerous Latilactobacillus, Leuconostoc, and Carnobacterium species, among which the most frequently detected were Latilactobacillus sakei, Latilactobacillus sakei carnosum, Leuconostoc mesenteroides, and Carnobacterium divergens. Some products presented more complex communities that encompassed Proteobacteria such as Moellerella wisconsensis, Proteus hauseri, Brochothrix thermosphacta, and less frequently Pseudomonas, Erwinia, and Massilia. Opportunistic pathogenic bacteria such as Escherichia coli and Vibrio sp. were found in small quantities. The yeasts Kazachstania servazzii and Debaryomyces hansenii occurred already at 0 days, whereas various species of Candida (Candida zeylanoides, Candida sake, Candida norvegica, and Candida glaebosa) were abundant only after 12 days. These results indicated that the microbiological contaminants overgrowing during the secondary shelf life did not derive from environmental cross-contamination at the opening of the tray but were already present when the packages were opened, highlighting the phases of production up to the packaging as those crucial in managing the safety risk associated to this product.

Keywords: cooked ham, secondary shelf life, food waste, Leuconostoc carnosum, Leuconostoc mesenteroides, Carnobacterium divergens 


\section{INTRODUCTION}

According to the Food and Agriculture Organization, food production in the world is higher than the demand and ensues a huge amount of wasted food per year, aggravating $\mathrm{CO}_{2}$ emissions, land utilization, and blue water consumption (FAO, 2013; Mekonnen and Gerbens-Leenes, 2020). This phenomenon is also reflected in a series of economic, ethical, and social repercussions, considering that $11 \%$ of the world's population has no access to food resources (Wohner et al., 2019). Unlike other food losses that may occur along the food production and supply chain, food wastes are recognized to take place in the last phases of the chain, i.e., the distribution, sale, and consumption, especially at the household level (FAO, 2013; Abdelradi, 2018; Salihoglu et al., 2018; UNEP, 2021). The assessment of appropriate secondary shelf life, defined as the time after package opening during which the food product retains a required level of quality, is pivotal for reducing domestic food waste (Nicosia et al., 2021). Indeed, excessively short secondary shelf life suggested by producers, if not relying on scientific data, may mislead consumers to discard foods still suitable for consumption.

The highest cost in wasted resources is associated with animal-based foods, which have the highest value of footprint (FAO, 2013; Mekonnen and Gerbens-Leenes, 2020). Meat waste represents a major contribution to food losses in developed countries (FAO, 2011). The large availability of food, together with the greater awareness of health and hygiene risks associated with the consumption of altered meat, means that meat products are not generally consumed beyond the expiration date or are rejected due to spoilage or minimal undesirable features perceived as defects (Iulietto et al., 2015; Ojha et al., 2020). The changes in consumers' lifestyles have also led to the increasing demand for ready-to-eat products (Bonifacie et al., 2021). Among them, sliced cooked ham in modified atmosphere packaging (MAP) is a main product of the meat processing industry. Although cooked ham undergoes cooking at $\mathrm{T} \geq 70^{\circ} \mathrm{C}$, bacterial proliferation occurs during the whole shelf life even after maintaining hygienic precautions and preservative procedures (Raimondi et al., 2019), and a throughout survey on the sources of contamination after the cooking is still lacking.

Sliced cooked ham in MAP is subjected to abundant microbial contamination throughout production and shelf life, which leads to deterioration of both sensorial properties and wholesomeness. The microbiota of this product has been the subject of several studies, consistently indicating lactic acid bacteria (LAB) as the main contaminants that proliferate throughout the shelf life and reach remarkably high counts of $10^{7}-10^{9} \mathrm{cfu} / \mathrm{g}$ (Menezes et al., 2018; Raimondi et al., 2019). Temperature, pH, water activity, nutrient availability, redox potential, and gas composition trigger microbial growth (Iulietto et al., 2015), affecting the preservation of food along the cold chain and consequently influencing the wastage (Vasilopoulos et al., 2008). LAB may concur with meat preservation due to the production of organic acids and hydrogen peroxide, which exert an intrinsic antimicrobial effect. Furthermore, selected strains produce bacteriocins specifically inhibiting certain contaminating pathogen bacteria, such as Listeria (Raimondi et al., 2021). On the other hand, LAB may contribute to spoilage of MAP cooked ham, inducing discoloration, changes in odor, flavor, and texture, and slime formation, negatively affecting the shelf life (Samelis et al., 2000; Kreyenschmidt et al., 2010; Raimondi et al., 2019). The spoilage of LAB is mainly caused by homofermentative bacteria belonging to the species Latilactobacillus curvatus and Latilactobacillus sakei or heterofermentative such as Leuconostoc carnosum, Leuconostoc gelidum, Carnobacterium divergens, and Carnobacterium maltaromaticum, whereas the Listeriaceae Brochothrix thermosphacta occurs when oxygen is present inside the packages (Vasilopoulos et al., 2008; Hu et al., 2009; Raimondi et al., 2019).

Some information is available on the evolution of microbial and sensorial properties of MAP cooked ham throughout the shelf life, but the evolution of the product after the opening of the package has not been investigated so far (Vasilopoulos et al., 2008; Kreyenschmidt et al., 2010; O’Neill et al., 2018; Raimondi et al., 2019). In this work, we studied the secondary shelf life of MAP cooked hams of five Italian industries, simulating the storage in a domestic fridge. Detailed information on the evolution of the products, including microbiological, sensorial, and chemical features, was collected for a period of 12 days after the opening of packages to provide the scientific basis for a more accurate recommendation of the secondary shelf life of MAP cooked ham.

\section{MATERIALS AND METHODS}

\section{Sample Collection and Experimental Design}

Samples of MAP sliced cooked ham produced by five selected industries were purchased in local markets (Modena, Italy). For each of the five products, three packages with the same expiration date ( \pm 3 days) were purchased. This kind of product available in the Italian market has a shelf life of typically 4 weeks; all the selected packages had at least 2 weeks of remaining shelf life at the purchase time. Where reported, the producers suggest food consumption within 1-3 days after package opening. Ingredients and nutritional composition are reported in Supplementary Table 1. Microbiological, chemical, and sensorial analyses were carried out at the opening of packages (0 days), then every 4 days (4, 8, and 12 days), during which the samples were maintained in plastic bags within the same domestic refrigerator set to $4^{\circ} \mathrm{C}$. The actual temperature of the domestic refrigerator was monitored and recorded using a probe and data logger (mini TH, XS Instruments, Carpi, Italy).

All chemicals were purchased from Sigma-Aldrich (St. Louis, MO, United States) unless otherwise stated.

\section{Sensorial Evaluation and Spoilage Assessment}

At each time point, a slice of cooked ham was allowed to reach room temperature for $15 \mathrm{~min}$; then, sensory analyses were carried out by a trained sensory panel. Occurring defects were evaluated through odor, texture, and color descriptors, which were given a score in the range between 0 (no defects, highest sensory quality) and 5 (highest level of defects, lowest sensory quality). 


\section{Chemical Analyses}

The $\mathrm{pH}$ was measured in five distinct points per sample using a puncture electrode (Sension + electrode 5,233, $\mathrm{HACH}$, Switzerland). Organic acids, glucose, and ethanol were determined by high-performance liquid chromatography, according to Vasilopoulos et al. (2008). Volatile organic compounds (VOCs) were tracked by headspace solid-phase microextraction coupled with gas chromatographymass spectrometry analysis, following the protocol described by Raimondi et al. (2018).

\section{Microbiological Analyses}

Ten grams of cooked ham was suspended and homogenized in saline peptone water $(8.5 \mathrm{~g} / \mathrm{L} \mathrm{NaCl}$ and $1 \mathrm{~g} / \mathrm{L}$ peptone $)$ at the concentration of $10 \%(\mathrm{w} / \mathrm{v})$ utilizing a Lab Blender Stomacher (Seward Medical, London, United Kingdom) for $4 \mathrm{~min}$. Appropriate decimal dilutions in saline peptone water were spread on agar plates for the enumeration and isolation of bacteria and fungi: plate count agar (PCA) for total aerobic bacteria, Lactobacilli MRS Agar for LAB, violet red bile glucose agar (VRBGA) for enterobacteria, and rose bengal chloramphenicol agar (RBCA) for fungi, and Baird-Parker agar (BPA) for putative staphylococci. The plates were incubated in aerobiosis at $30^{\circ} \mathrm{C}$ for $48 \mathrm{~h}$, except for RBC plates incubated at $25^{\circ} \mathrm{C}$ for 5-7 days and MRS plates incubated in an anaerobic jar at $30^{\circ} \mathrm{C}$ for $72 \mathrm{~h}$, with anaerobiosis generated by GasPaK (BD Difco). To detect Salmonella sp., the initial suspension was pre-enriched for $24 \mathrm{~h}$ at $30^{\circ} \mathrm{C}$, and $100 \mu \mathrm{l}$ was seeded in $10 \mathrm{ml}$ of Rappaport-Vassiliadis soy peptone broth and incubated for $24 \mathrm{~h}$ at $41^{\circ} \mathrm{C}$. The enrichment culture was then seeded on xylose lysine deoxycholate plates and incubated for $24 \mathrm{~h}$ at $37^{\circ} \mathrm{C}$. All the media were purchased from BD Difco (Franklin Lake, NJ, United States).

After enumeration, a representative number of colonies (up to 48 colonies per sample per medium) were randomly picked up from PCA, MRSA, RBCA, VRBGA, and BPA and streaked in the same medium. Instagene Matrix (Bio-Rad Laboratories, Redmond, WA, United States) was used for the extraction of polymerase chain reaction (PCR) amplifiable DNA. The clones were amplified with M13-random amplified polymorphic DNA (RAPD) primer (5'-GAGGGTGGCGG TTCT- $\left.{ }^{\prime}\right)$, and the ensuing RAPD-PCR profiles were clustered in biotypes with $>75 \%$ similarity by Pearson correlation coefficient (Quartieri et al., 2016). A single strain for each biotype was taxonomically characterized by sequencing the $\mathrm{V} 1-\mathrm{V} 3$ portion of the 16S ribosomal RNA (rRNA) gene for bacteria and the ITS1 for fungi. The couples of primers 16S-500f ( $5^{\prime}$-TGG AGA GTT TGA TCC TGG CTC AG-3')/16S-500r (5'-TAC CGC GGC TGC TGG CAC- $\left.3^{\prime}\right)$ and ITS1( $5^{\prime}$-TCC GTA GGT GAA CCT TGC GG$\left.3^{\prime}\right) /$ ITS4 (5'-TCC TCC GCT TAT TGA TAT GC-3') were utilized to amplify the two target regions, respectively (White et al., 1990; Kolbert et al., 2004). Comparisons with the reference sequences available in the GenBank database were obtained by the National Center for Biotechnology Information BLAST software ${ }^{1}$.

${ }^{1}$ https://blast.ncbi.nlm.nih.gov

\section{S Ribosomal RNA Gene Profiling}

Metataxonomic analysis was performed when packages were opened ( 0 days) and after 8 days, when sensorial properties were still acceptable. Two grams of cooked ham was collected and homogenized in $10 \mathrm{ml}$ of food lysis buffer (DNeasy Mericon Food Kit; Qiagen, Hilden, Germany), and total DNA was extracted following the manufacturer's standard protocol. DNA concentration was adjusted to $5 \mathrm{ng} / \mu \mathrm{l}$ after quantification with a Qubit 3.0 fluorimeter (Thermo Fisher Scientific, Waltham, MA, United States). Partial 16S rRNA gene sequences were performed by a DNA sequencing service provider (Eurofins Genomics, Ebersberg, Germany), which amplified and sequenced the V3-V4 region of the $16 \mathrm{~S}$ rRNA gene using an Illumina MiSeq instrument (Illumina, San Diego, CA, United States). The sequences are available in the National Center for Biotechnology Information repository with the BioProject ID.

Raw sequences were analyzed with the QIIME 2.0 pipeline, version 2021.4 (Bolyen et al., 2019), with appropriate plugins for trimming (CUTADAPT) and denoising (DADA2) into amplicon sequence variants (Martin, 2011; Callahan, 2016). Taxonomy assignment was carried out with the feature classifier VSEARCH (Rognes et al., 2016), with SILVA SSU database release 138.1 as a reference $\left({ }^{2}\right.$ note that the database, despite being the latest, is not up to date with the most recent nomenclature changes in the Lactobacillaceae and Leuconostocaceae families), and similarity threshold set at 0.97. The appropriate QIIME2 plugins were utilized to compute the alpha diversity (Chaol and Pielou's evenness) and beta diversity (Bray-Curtis dissimilarity) and to compare them within and between 0 - and 8-day samples (i.e., the Kruskal-Wallis test for alpha diversity; permutational multivariate analysis of variance for beta diversity). Differences were considered significant for $P<0.05$. Principal coordinate analysis was computed with QIIME2, based on the beta-diversity distance matrix.

\section{Statistical Analysis}

Unless otherwise specified, values were reported as means $\pm \mathrm{SD}$ of triplicate samples. The comparison was performed according to Student's $t$-test or one-way analysis of variance followed by Tukey post hoc comparisons, using the MaxStat software (MaxStat Pro, version 3.6).

Kruskal-Wallis test followed by Dunn's non-parametric post-comparison test was performed on sensorial properties. Differences were considered statistically significant for $P<0.05$.

Principal component analysis (PCA) was used to explore the data matrix of VOCs with size $\{60,157\}$, including the 157 relative areas of VOCs, determined for the three replicates of each product at the four time points. The number of significant principal components (PCs) was defined using the screen plot, which reports the percentage of variance explained by each PC vs. the PC number. The PCA model was calculated using Past version 3.14 (Hammer et al., 2001).

Linear discriminant analysis effect $\operatorname{size}^{3}$ was utilized to discover distinctive taxonomic features characterizing samples

\footnotetext{
${ }^{2}$ https://www.arb-silva.de/download/arb-files/

${ }^{3}$ http://huttenhower.sph.harvard.edu/galaxy
} 
at 0 and 8 days (Segata et al., 2011). Taxa presenting a significant differential abundance $(P<0.05)$ and logarithmic, linear discriminant analysis score $>2$ were considered as microbial biomarkers of the corresponding timepoint.

\section{RESULTS}

Sliced cooked ham trays in MAP of five commercial products were stored for 12 days in a domestic refrigerator, and the temperature profile was reconstructed through a data logger. Values ranged between 4.1 and $6.5^{\circ} \mathrm{C}$ (Supplementary Figure 1), with a mean temperature of $5.2 \pm 0.6^{\circ} \mathrm{C}$ (mean $\pm \mathrm{SD}$ ). The temperature fluctuated in a narrow range that was well representative of possible domestic storage without drastic temperature abuse. It should be noted that the domestic storage temperature suggested on labels is usually $0-4^{\circ} \mathrm{C}$ : even if the measured temperature falls out of this range, it should be considered as a realistic condition, based on previous data collected in different domestic refrigerators, which ranged from 4.6 to $10^{\circ} \mathrm{C}$ (Nicosia et al., 2021).

\section{Spoilage Assessment}

The sensorial properties of cooked ham samples were evaluated at the time of first opening and after 4, 8, and 12 days of secondary shelf life. Generally, negative changes were recorded after 8 days, and the products became unacceptable after 12 days. The most relevant modifications were the emergence of acid flavor, rotten smell, and discoloration (Figure 1). Products behaved differently during this lapse of time. At 8 days, discoloration of D samples was significantly more pronounced than that of $\mathrm{C}$ and $\mathrm{E}$ ones $(P<0.05)$, and the overall extent of spoilage was higher in $\mathrm{D}$ than in other samples. At 12 days, significantly higher scores of rotten smell were registered for samples $\mathrm{C}, \mathrm{D}$, and $\mathrm{E}$ compared with $\mathrm{A}$ and $\mathrm{B}(P<0.05)$; furthermore, the whole spoilage was higher in $\mathrm{D}$ than in $\mathrm{A}$ and $\mathrm{B}(P<0.05)$. Samples $\mathrm{C}$ and $\mathrm{D}$ presented a reduction of drip and an increase of discoloration, rotten smell, and acidity flavor $(P<0.05$; Supplementary Table 2$)$.

\section{Culture-Dependent Enumeration}

Viable counts on PCA, MRSA, VRBGA, RBCA, and BPA plates were utilized to monitor total aerobic bacteria, LAB, putative enterobacteria, staphylococci, fungi, and staphylococci, respectively, throughout the secondary shelf life (Figure 2).

Total aerobic bacteria ranged between 5.8 and $9.0 \mathrm{Log} \mathrm{cfu} / \mathrm{g}$ $(7.8 \pm 0.7 \mathrm{Log} \mathrm{cfu} / \mathrm{g}$, mean $\pm \mathrm{SD})$ at 0 days, without significant differences among the products $(P>0.05)$. After 4,8 , and 12 days of fridge storage, total aerobic bacteria significantly increased in packages of product $\mathrm{D}$, which progressively became the most contaminated $(P<0.05)$. A significant increase was also observed for products $\mathrm{A}$ and $\mathrm{C}$, whereas products $\mathrm{B}$ and $\mathrm{E}$ did not exhibit any significant change.

The initial charge of LAB widely differed among samples being comprised from 5.7 to $9.1 \mathrm{Log} \mathrm{cfu} / \mathrm{g}(7.7 \pm 0.9 \mathrm{Log} \mathrm{cfu} / \mathrm{g}$, mean $\pm \mathrm{SD}$ ), with product $\mathrm{D}$ samples presenting the lowest values $(P<0.01)$. After 4,8 , and 12 days, the spread became narrower, with LAB charges lying in the range of 7-9 Log cfu/g (mean $=8.3 \mathrm{Log} \mathrm{cfu} / \mathrm{g})$. Throughout the secondary shelf life, LAB significantly increased in samples of products $C$ and $D$, with the latter progressively becoming the richest $(P<0.05)$. In the other products, LAB remained unchanged.

Initially, putative enterobacteria lay below the limit of detection in most of the samples of products A, B, and C, whereas all the samples of products $\mathrm{D}$ and $\mathrm{E}$ presented contamination in the range of 3.0 and $6.7 \mathrm{Log} \mathrm{cfu} / \mathrm{g}$, without significant differences between them $(P>0.05)$. Throughout the secondary shelf life, putative enterobacteria increased up to $9.7 \mathrm{Log} \mathrm{cfu} / \mathrm{g}$ in D samples $(P<0.05)$, whereas they remained unchanged in $\mathrm{E}$ samples $(P>0.05)$. After 12 days, Enterobacteriaceae also appeared in a few samples of products $A$ and $B$, which presented a load up to 3.3 Log cfu/g, whereas they were never found in product $C$.

Fungi were initially found only in three samples (A3, B2, and B3). In A samples, the load of fungi increased over time, reaching $5.0 \pm 0.6$ at T12. After 12 days, fungi were isolated from most of the samples (11 of 15), with a mean charge of $4.9 \pm 1.0 \mathrm{Log} \mathrm{cfu} / \mathrm{g}$.

Putative staphylococci and Salmonella sp. were analyzed after 12 days of secondary shelf life. Putative staphylococci were found in A, D, and E samples, with counts ranging between 2.5 and 6.9 Log cfu/g (Supplementary Table 3). Salmonella sp. was absent in all the samples.

\section{Identification of the Isolates}

Five hundred sixty isolates were selected from plates at 0 and 12 days and were clustered into 68 dominant biotypes, according to RAPD-PCR fingerprinting (Supplementary Table 4). One representative of each biotype was subjected to the sequencing of the 16S rRNA gene or ITS to obtain species designation.

The clones isolated in PCA belonged to 25 biotypes belonging to 11 species: C. divergens (5), L. sakei (5), Leuconostoc mesenteroides (5), L. carnosum (2), Bacillus nealsonii (1), Candida zeylanoides (1), Carnobacterium gallinarum (1), C. maltaromaticum (1), Carnobacterium sp. (1), Massilia aurea (1), Moellerella wisconsensis (1), and Proteus hauseri (1). The clones isolated in MRSA belonged to 15 biotypes, attributed to the species L. sakei (7), L. mesenteroides (3), L. carnosum (2), C. divergens (1), L. curvatus (1), and Weissella viridescens (1). Six strains were isolated from VRBGA plates, belonging to the species Erwinia billingiae (2), Massilia arvi (1), M. wisconsensis (1), P. hauseri (1), and Pseudomonas sp. (1). Thirteen different biotypes were found on RBCA plates, belonging to the species C. zeylanoides (5), Kazachstania servazzii (3), Candida glaebosa (1), Candida novergica (1), Candida sake (1), Debaryomyces hansenii (1), and Debaryomyces spp. (1). The nine biotypes were isolated on BPA plates at T12 that belonged to the species P. hauseri (5), Staphylococcus xylosus (2), Corynebacterium stationis (1), and Kocuria spp. (1).

Leuconostoc mesenteroides and/or L. carnosum abundantly contaminated the samples belonging to products $\mathrm{A}, \mathrm{B}, \mathrm{C}$, and $\mathrm{E}$, occurring already at 0 days and after 12 days in the magnitude of 7-8 Log cfu/g in PCA or MRSA plates (Table 1). In product D, a high load of L. carnosum (up to $8.9 \mathrm{Log} \mathrm{cfu} / \mathrm{g}$ ) appeared only after 12 days. L. sakei was found only in samples of products $\mathrm{A}, \mathrm{B}$, and $\mathrm{E}$, being generally found in the magnitude of 6-8 Log $\mathrm{cfu} / \mathrm{g}$ MRSA in plates both at 0 and 12 days. In product C, L. sakei 

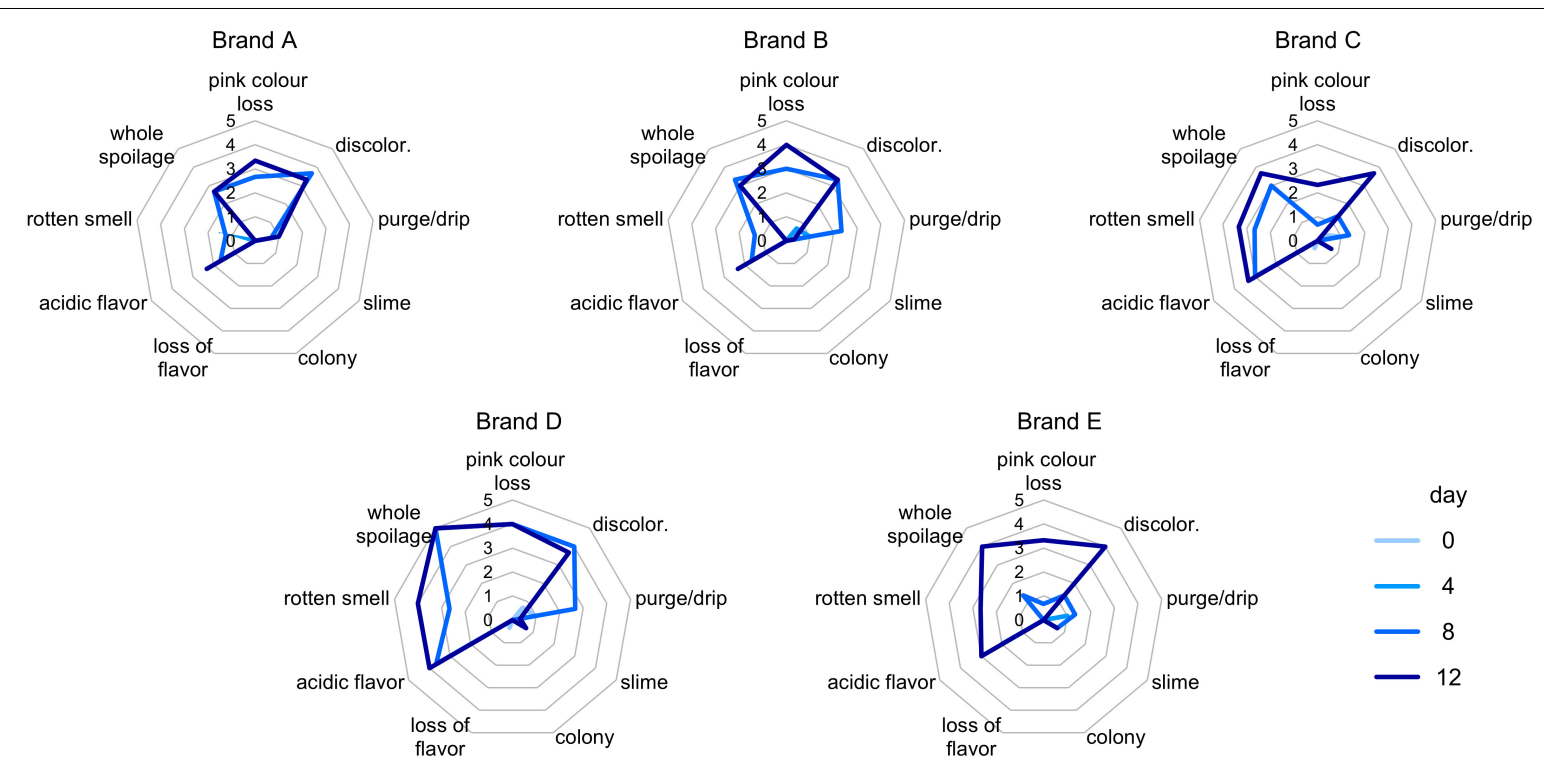

FIGURE 1 | Spider charts for scores (0-5) of sensory defects detected in (A-E) samples, with different color lines for each timepoint.

occurred only at 0 days. C. divergens characterized only samples of products $\mathrm{D}$ and $\mathrm{E}$, being present already at 0 days, generally in the magnitude of $7 \mathrm{Log} \mathrm{cfu} / \mathrm{g}$, and reaching up $9 \mathrm{Log} \mathrm{cfu} / \mathrm{g}$ after 12 days. C. gallinarum and other Carnobacterium sp. occurred only in samples of product $\mathrm{C}$, at 0 and 12 days, respectively. Interestingly, only for $\mathrm{C}$ samples, all the biotypes of the isolates at both 0 and 12 days were LAB. W. viridescens occurred only after 12 days in two samples of product $\mathrm{D}$, where it reached the remarkable concentration of $9.1 \mathrm{Log} \mathrm{cfu} / \mathrm{g}$.

Contamination with $M$. wisconsensis was observed only in D and $\mathrm{E}$ products, both at the opening of packages and after 12 days. At both the time points, the load of $M$. wisconsensis was very variable, ranging from 2.0 to $9.7 \mathrm{Log} \mathrm{cfu} / \mathrm{g}$, the highest value being observed in a sample of product D after 12 days. Other Gramnegative species (i.e., E. billingiae, M. arvi, M. aurea, P. hauseri, and Pseudomonas sp.) appeared sporadically in a single sample of different products and generally in low amounts (2-3 Log cfu/g).

Most of the yeast strains were isolated at 12 days, belonging to different species of the genus Candida (C. glaebosa, C. norvegica, C. sake, and C. zeylanoides); an exception was represented by $K$. servazzii that was detected in sample B since T0 reaching up to $5.8 \mathrm{Log} \mathrm{cfu} / \mathrm{g}$ at the last time point.

\section{Analysis of Microbial Population by $16 s$ Ribosomal RNA Gene Profiling}

Metataxonomic analysis was performed at the opening and after 8 days of secondary shelf life when samples were not yet spoiled. The metagenomic survey of $16 \mathrm{~s}$ rRNA gene profiling yielded $52,964-148,150$ reads per sample, with a total of $3,442,935$ in 30 samples. The reads were dereplicated into 822 amplicon sequence variants hitting a reference sequence in the Silva database and collapsed at the seventh level of taxonomic annotation into 326 operational taxonomic units. The microbiota of cooked ham was largely dominated by Proteobacteria and Firmicutes phyla (Figure 3). Chaol richness was different among the diverse products, being highest for $\mathrm{C}$ samples and lowest for $\mathrm{A}$ and $\mathrm{D}$ ones (Supplementary Figure 2A). Only in D samples, richness significantly decreased after 8 days of conservation. Pielou evenness presented significant differences among the samples and showed similar levels of diversity within the same product, excluding relevant variations during the secondary shelf life (Supplementary Figure 2B). In evenness, samples of product D collected at both 0 and 8 days showed the greatest variability.

In the principal coordinate analysis plot computed from the Bray-Curtis beta diversity distance matrix (Figure 4A), initial samples could not be clearly separated from those with 8 days of secondary shelf life. On the other hand, samples clustered based on the product, regardless of the timepoint. Samples of products A and D clustered together and shared some biomarkers such as Lactobacillus (comprising Latilactobacillus) and L. mesenteroides that mainly contributed to PCo1 (Figure 4B). Accordingly, A and D samples were dominated by Firmicutes, mainly ascribed to the families of Leuconostocaceae and Lactobacillaceae, currently reclassified into a single-family named Lactobacillaceae (Figure 3).

Generally, the evolution of the 15 samples during the first 8 days of secondary shelf life did not determine relevant changes, with a few exceptions (B2, C1, and C3). The microbiota composition of $\mathrm{A}, \mathrm{D}$, and $\mathrm{E}$ products was minimally perturbed over the first 8 days of secondary shelf life.

B samples lay contiguously at low PCo1 and PCo2 values, characterized by $M$. wisconsensis and C. divergens. Consistently, in five of six B samples, M. wisconsensis outnumbered the other bacteria.

E samples clustered together (high PCo1 and low PCo2 values), with C. maltoaromaticum and Leuconostoc as major biomarkers. Accordingly, the families Leuconostocaceae 

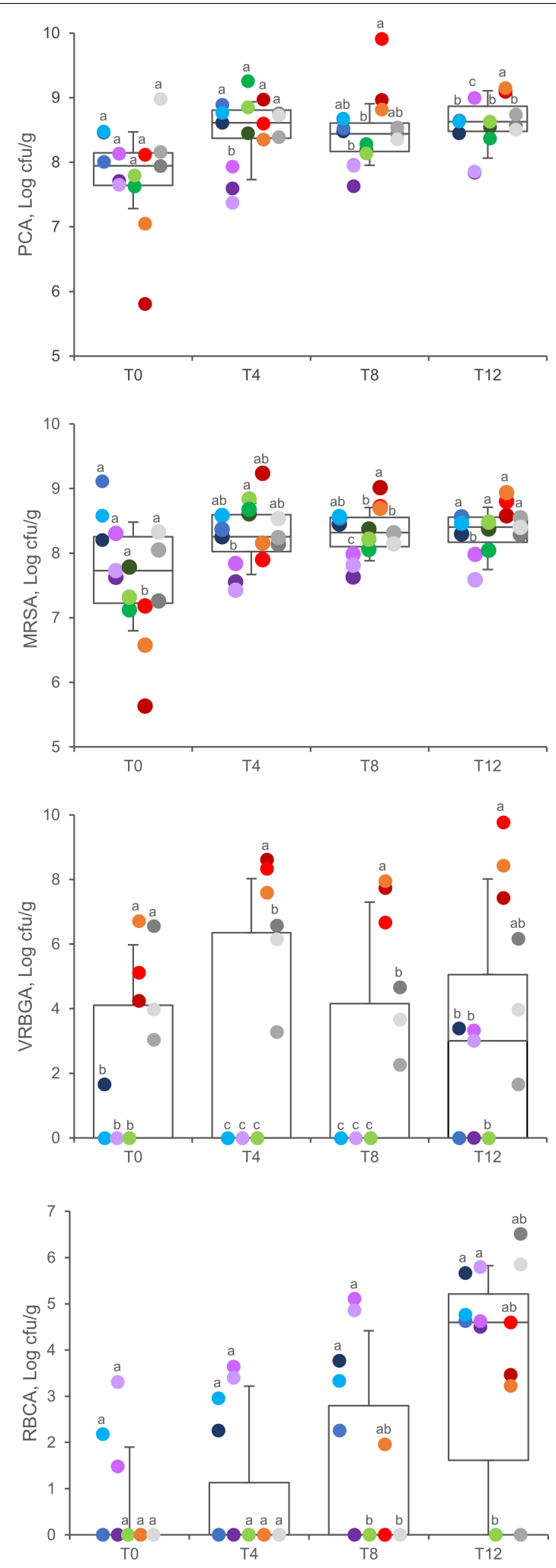

FIGURE 2 | Viable counts in PCA, MRSA, VRBGA, and RBCA plates of A (blue), B (violet), C (green), D (red), and E (gray) samples. Boxes indicate 25th, 50th, and 75th percentiles; whiskers indicate 10th and 90th percentiles. Within each time point, products sharing same letter did not make a significant difference $(p>0.05)$. (currently comprised in Lactobacillaceae), Carnobacteriaceae, and Morganelaceae dominated E samples (Figure 3). Other common bacteria identified in all E samples were Lactobacillus (comprising Latilactobacillus), Pseudomonas, Psychrobacter, Photobacterium, Xanthomonas, Proteus, Serratia, Providencia, Citrobacter, Aeromonas, Shewanella, Acinetobacter, Vibrio, Hafnia-Obesumbacterium, Klebsiella, Brochothrix, and Halomonas.

Linear discriminant analysis effect size algorithm was utilized to discover distinctive taxonomic features characterizing samples at 0 or 8 days. Only Bacillaceae, Geobacillus, and Parageobacillus thermoglucosidasius exhibited significantly higher abundances in samples at 0 days (Supplementary Figure 3). The same analysis, applied to identify biomarkers specific for each product, indicated that product $\mathrm{B}$ was characterized by $L$. mesenteroides, product $\mathrm{D}$ by Enterobacterales and Morganellaceae, and product $\mathrm{E}$ by Photobacterium.

\section{Glucose and Organic Acids}

Glucose initially ranged from 0.09 to $0.68 \% \mathrm{w} / \mathrm{w}$ (g per $100 \mathrm{~g}$ of ham) (Figure 5). Its concentration was significantly higher in D and $\mathrm{E}$ samples than in $\mathrm{A}, \mathrm{B}$, and $\mathrm{C}$ ones. Overall, it significantly decreased during the secondary shelf life $(P<0.05)$. However, after 12 days of refrigeration at $5^{\circ} \mathrm{C}$ and relevant metabolic activity, it was still present in most samples (11 of 15) although in negligible amounts ( 0.01 to $0.17 \% \mathrm{w} / \mathrm{w})$.

Lactic acid was the main metabolite, occurring in all the samples and at all the timepoints throughout the secondary shelf life. The initial concentration ranged from 0.15 to $0.62 \% \mathrm{w} / \mathrm{w}$, with the highest levels in product A samples $(P<0.05)$. Lactic acid significantly increased during the secondary shelf life in B, C, and $\mathrm{E}$ samples $(P<0.05)$, where its concentration almost doubled (from $0.30 \pm 0.14$ to $0.71 \pm 0.01$; from $0.26 \pm 0.07$ to $0.70 \pm 0.06$; from $0.38 \pm 0.02$ to $0.68 \pm 0.02$ in $\mathrm{B}, \mathrm{C}$, and $\mathrm{E}$, respectively), whereas it did not significantly increase in $\mathrm{A}$ and $\mathrm{D}$ samples.

Acetic acid was another major metabolite that accumulated in cooked ham over time. In all the samples, its concentration was under the limit of detection at both 0 and 4 days, whereas it accumulated toward the end of the secondary shelf life. Ethanol was detected in minor amounts, without significant differences among the products, generally tending to accumulate over time.

The $\mathrm{pH}$ of cooked ham decreased progressively during the secondary shelf life $(5.7 \pm 0.3$ at $\mathrm{T} 0 ; 5.5 \pm 0.4$ at $\mathrm{T} 4 ; 5.4 \pm 0.3$ at T8; $5.3 \pm 0.3$ at T12; overall means $\pm \mathrm{SD})(P<0.01)$, with different kinetics depending on the product.

\section{Volatile Organic Compounds}

In the headspace of cooked ham samples, solid-phase microextraction coupled with gas chromatography analysis revealed a total of 157 VOCs, including organic acids, ethanol, and other alcohols, ketones, fatty aldehydes, esters, phenols, and a variety of aromatic compounds, furans, linear and branched aliphatic hydrocarbons, terpenoids, and sulfides (Supplementary Figure 4).

In the PCA model of VOC profiles, the two most informative dimensions, PC1 and PC2, accounted for 47 and 31\% of data variability, respectively (Figure 6A). Ethanol, acetic acid, and 
TABLE 1 | Dominant microbial contaminants isolated from PCA (P), MRSA (M), VRBGA (M), RBCA (R), and BPA (B) plates at 0 and 12 days of secondary shelf life.

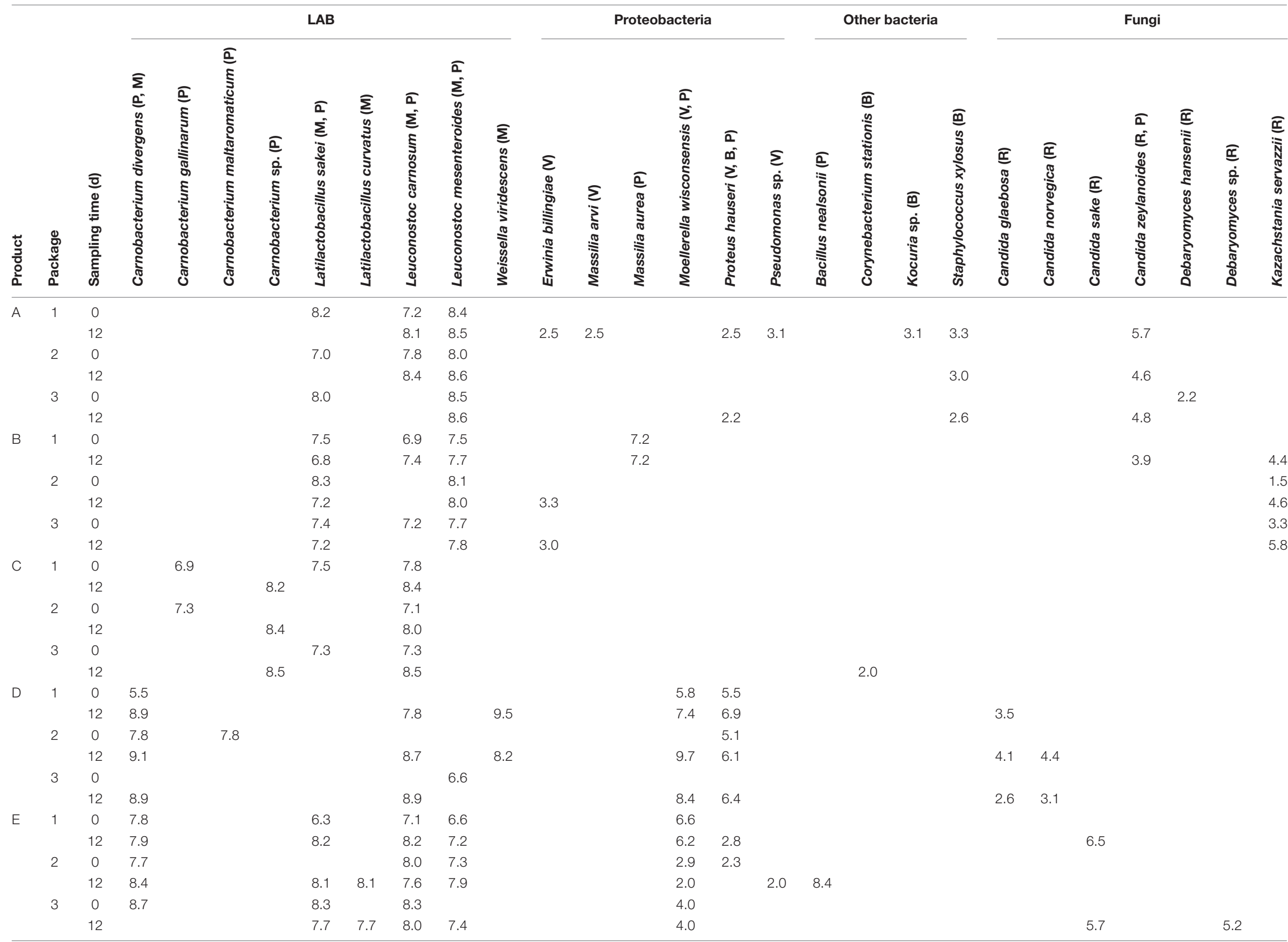

Isolates were genotyped by RAPD-PCR fingerprinting and subjected to $16 S$ rRNA gene or ITS sequencing to obtain a taxonomic designation. Concentration, inferred from plate counts, is reported as Log cfu/g. 


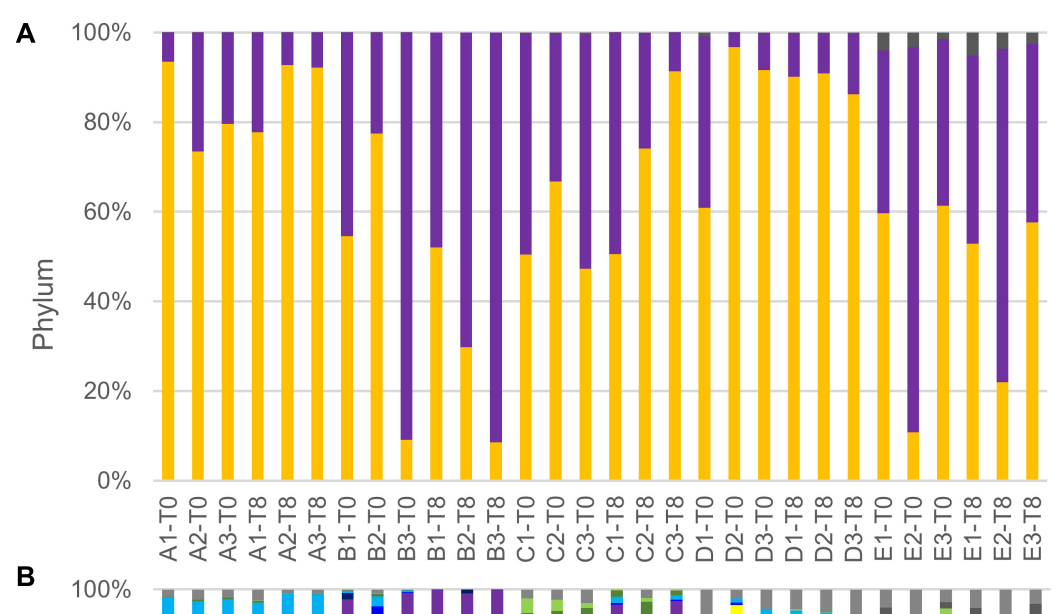

- Other $(<1 \%) /$ Unidentify

- Proteobacteria

- Firmicutes

B

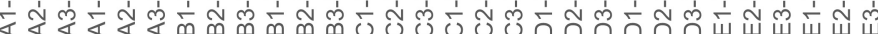

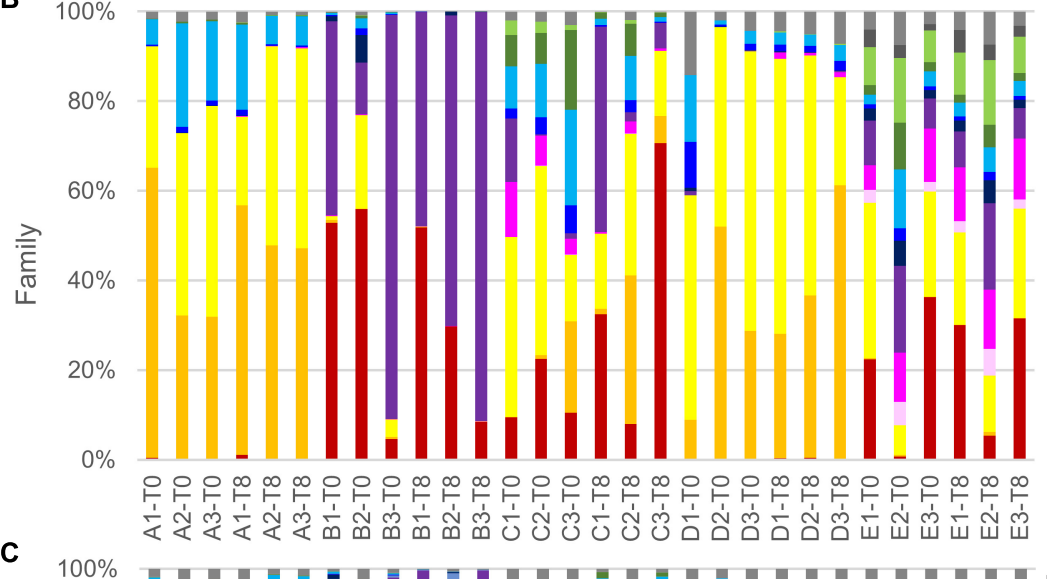

- Other $(<5 \%)$

- Bacteria uncultured

- Xanthomonadaceae

- Vibrionaceae

- Pseudomonadaceae

- Moraxellaceae

- Yersiniaceae

- Morganellaceae

- Enterobacteriaceae

Aeromonadaceae

Leuconostocaceae

- Lactobacillaceae

- Carnobacteriaceae

C

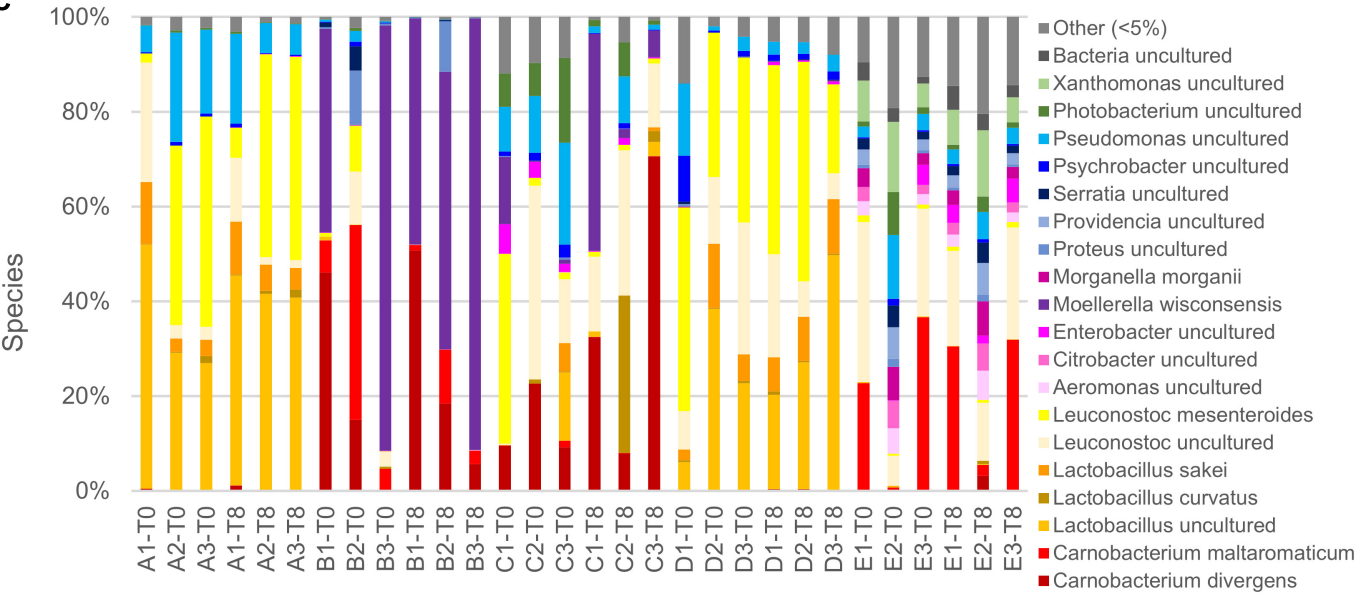

FIGURE 3 | Relative abundance of main phyla (A), families (B), and species (C) in slices of cooked ham of five different products at packages opening and after 8 days. Note that in reference database, despite being latest update, Leuconostocaceae and Lactobacillaceae are reported as two separated families, but, accordingly, current nomenclature are included in sole family Lactobacillaceae. Moreover, species Lactobacillus sakei and Lactobacillus curvatus are not updated to recent name Latilactobacillus sakei and Latilactobacillus curvatus.

acetoin presented a major loading in determining differences among samples throughout the secondary shelf life. Acetoin, 3-methyl-1-butanol, and 2-3 butanediol presented a positive contribution to PC1, whereas ethanol and acetic acid presented a negative one (Figure 6B). Interestingly, only product $\mathrm{D}$ was characterized by higher values of PC1 compared with other products, but differences became evident only during the secondary shelf life, with increasing PC1 values over time. Acetic acid was the main positive contributor to PC2. All samples at 0 days were grouped at low values of PC1 and PC2, regardless of the product. A common trend of all products was the accumulation of acetic acid: the distribution of samples along the PC2 clearly showed a correlation between increasing time from the opening of the trays and increasing values of PC2. 

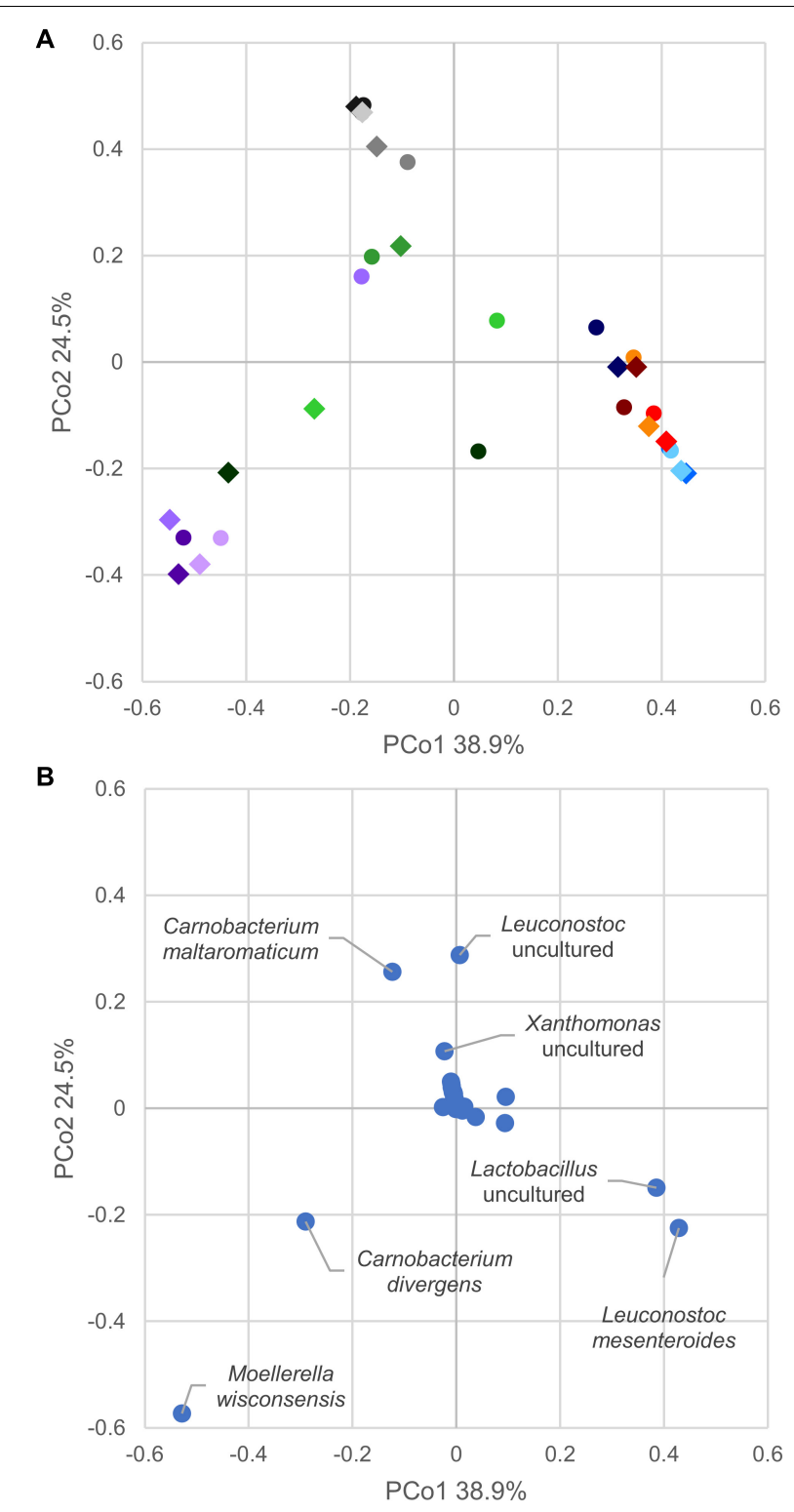

FIGURE 4 | (A) Principal coordinate analysis plot of beta diversity based on Bray-Curtis dissimilarity index of cooked ham microbiome. Different colors indicate products, A (blue), B (violet), C (green), D (red), and E (gray). Circles mark samples at opening, diamond after 8 days. (B) Principal coordinate analysis plot of species contribution to sample differentiation.

\section{DISCUSSION}

Modified atmosphere packaging sliced cooked ham is a popular ready-to-eat product that has been the subject of several studies aiming to define its microbiota and the deriving impact on safety, spoilage, and preservation (Vasilopoulos et al., 2010; Raimondi et al., 2019; Zagdoun et al., 2020; Candeliere et al., 2021). In this study, the microbial load and the chemical-physical characteristics of cooked ham were monitored for a period of 12 days after the opening of the packages, during which the products were stored in a domestic refrigerator. All the products
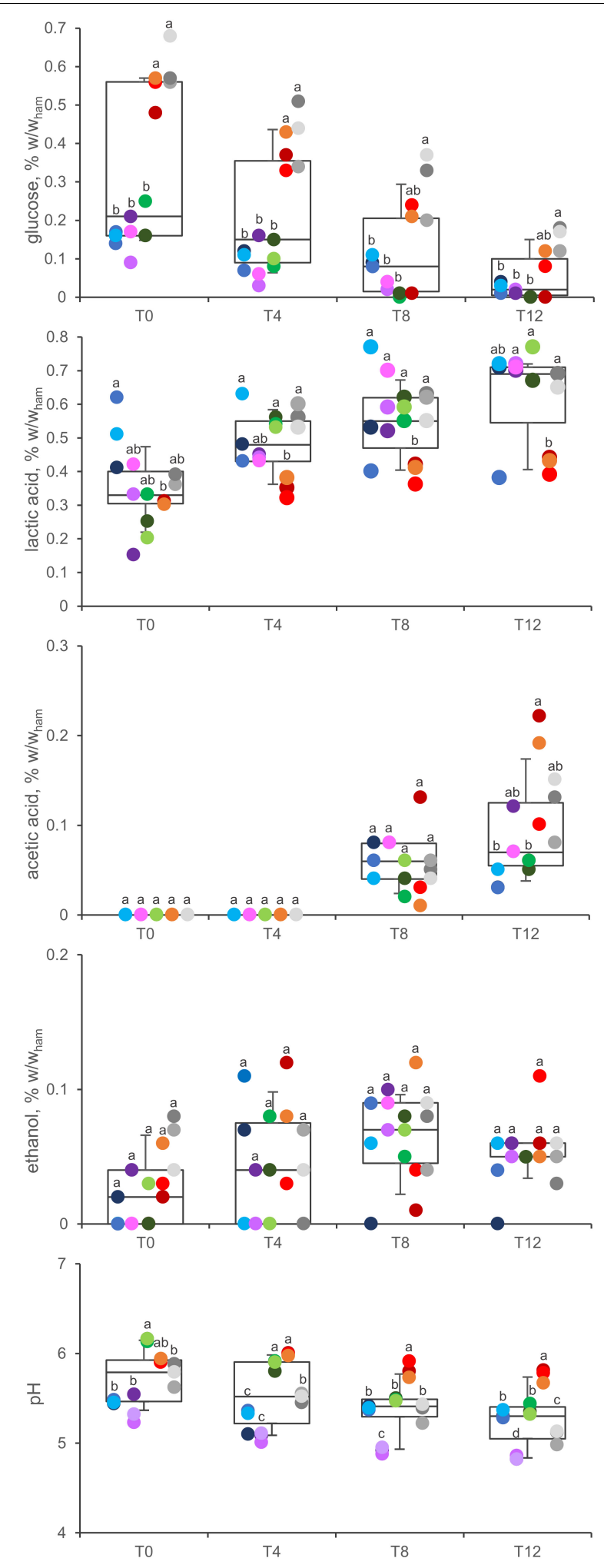

FIGURE 5 | Concentration of glucose, acetic acid, lactic acid, ethanol, and $\mathrm{pH}$ variation in A (blue), B (violet), C (green), D (red), and E (gray) samples. Boxes indicate 25th, 50th, and 75th percentiles; whiskers indicate 10th and 90th percentiles. Within each time point, products sharing same letter did not make a significant difference $(p>0.05)$. 
were purchased, opened, and analyzed in a range of 10-15 days before the expiration date. During the secondary shelf life at a mean temperature of $5.2 \pm 0.6^{\circ} \mathrm{C}$, the sensorial analyses of five products of MAP sliced cooked ham revealed a perceivable decay of quality after 8 days, but products became unacceptable only after 12 days, with the comparison of acid flavor, rotten smell, and discoloration. The organoleptic properties of the samples during the secondary shelf life suggest that cooked ham remains sensorially acceptable far beyond the 1-3 days suggested by the producers (Supplementary Table 1). However, the composition of the spoiling microbiota raised some concerns. The absence of viable Salmonella sp. in $10 \mathrm{~g}$ of the product after 12 days of storage is satisfying; nevertheless, the recurrent or sporadic presence of other opportunistic pathogens, such as E. coli, Vibrio sp., and Klebsiella pneumoniae, was identified by culture-independent methods and had relevant implications on the hygiene and safety of the products. Both metagenomic analysis and identification of the isolates revealed that, even at the opening of packages, all the products presented high microbial load and a quite rich microbiota, generally dominated by LAB. This result is in agreement with data reported in the literature indicating the genera Leuconostoc, Carnobacterium, and Latilactobacillus as among the main colonizers of MAP and vacuum-packed cooked ham (Vasilopoulos et al., 2010; Iskandar et al., 2017; Raimondi et al., 2019; Candeliere et al., 2021).

The 16S rRNA gene profiles were analyzed at the opening of packages and after 8 days of storing before samples became spoiled. The differences among microbiota were evident and mainly ascribed to the product, with LAB representing the prevailing group of bacteria in samples $A$ and $D$, whereas more complex communities, also encompassing several Proteobacteria, were identified in the others. For instance, the Enterobacteriaceae M. wisconsensis, a facultative anaerobic Gram-negative rod, was the major colonizer of $B$ samples already at 0 days. This species is probably an environmental contaminant, as literature reports a variety of isolation sources, including water, foods, and samples of human origin (Leroy et al., 2016). M. wisconsensis can be involved in the dissemination of antibiotic resistance, and its pathogenic role is debated (Stock et al., 2003; Leroy et al., 2016; Ahmad et al., 2020).

Culture-based identification revealed the presence of another contaminant, Enterobacteriaceae, $P$. hauseri. It is a Gram-negative motile bacterium, related to the human pathogens Proteus vulgaris and Proteus mirabilis, which was recurrent within the packages of products $\mathrm{A}$ and $\mathrm{D}$, where it increased to remarkably high levels of contamination at 12 days. Other Proteobacteria, belonging to the genera Pseudomonas, Erwinia, and Massilia, occurred less frequently and abundantly. Facultative anaerobic Gram-negatives evidently contaminated the product at some level during the processing and before the packaging and, like LAB, grew in the ham unhindered by the modified atmosphere (Stock et al., 2003; Kreyenschmidt et al., 2010; Drzewiecka, 2016). S. xylosus occurred only in product A. It is used as a biocontrol agent to preserve meat products from mycotoxin produced by fungi, can convert nitrates to nitrites, and is responsible for aroma components (Stahnke, 1994; Cebrián et al., 2020).
The metagenomic analysis pointed out the occurrence of other bacterial contaminants that were not retrieved with the culturedependent method and that could represent a potential concern for sensorial properties and/or food safety if they overgrew. $B$. thermosphacta, which is reported to give cooked ham sour offflavors, discoloration, and slime (Borch et al., 1996; Vasilopoulos et al., 2015; Dušková et al., 2016; Raimondi et al., 2019), was found in almost all the samples already at the beginning of the secondary shelf life, although in low amounts (up to 1.1\%). Opportunistic pathogenic bacteria were also identified, even if in small quantities. E. coli and Vibrio sp. were other frequent contaminants, being found in most of the samples, reaching up to 3.0 and $1.8 \%$ of the microbiota, respectively (means 0.5 and $0.2 \%$, respectively), whereas Salmonella enterica and K. pneumoniae occurred sporadically in a sole or few samples.

The presence of $K$. servazzii and $D$. hansenii already at 0 days confirms these yeast species as occasional contaminants of cooked meat products (Hernández et al., 2018), which colonized the products before the packaging and thrived during the secondary shelf life; indeed, once the packages have been opened, the protective effect of the modified atmosphere is lost, with only a slight residual inhibitory activity of the $\mathrm{CO}_{2}$ solubilized in the matrix. Yeast strains belonging to the genus Candida (C. zeylanoides, C. sake, C. norvegica, and C. glaebosa) lay below the limit of detection at the opening of packages but were abundantly found after 12 days. Although it could not be excluded that Candida spp. contaminated the cooked ham during the secondary shelf life, the appearance of C. sake, C. glaebosa, and $C$. zeylanoides seemed associated with specific products and could originate from the manufacturing. Frequent sources of yeast contamination are the surfaces of machinery entering in contact with meat during the processing (Hernández et al., 2018). The growth of yeasts is undesirable in meat products, as it causes off-flavors, discoloration, and the formation of slime (Nielsen et al., 2008).

Both culture-dependent and independent characterization of the spoiling microbiota suggested that the high load of bacteria already present at the opening of cooked ham packages prevented the bloom of other species and determined the outbreak of dominant bacteria. For example, a further increase of LAB was observed in the samples where they were already abundant at the opening of packages, leading Leuconostoc, Carnobacterium, Latilactobacillus, and, to a lower extent, Weissella to dominate these microbial communities. On the other hand, the growth of Gram-negatives and other bacteria occurred in samples initially characterized by a complex community, where LAB was not dominant. The increase of LAB somehow protected the samples from abundant contamination by other bacteria, concurring to the evolution of more safe products. In these samples, a similar role was exerted by several Latilactobacillus, Leuconostoc, and Carnobacterium species, among which the most frequently detected were L. sakei, L. carnosum, L. mesenteroides, and $C$. divergens. Generally, the low temperatures of storage made $L$. carnosum and $L$. mesenteroides the species best adapted to cooked ham (Vasilopoulos et al., 2008; Raimondi et al., 2021). Besides their preservative effect, LAB can also be involved in spoilage (Comi et al., 2016; Raimondi et al., 2019). L. mesenteroides, L. carnosum, and C. divergens were 

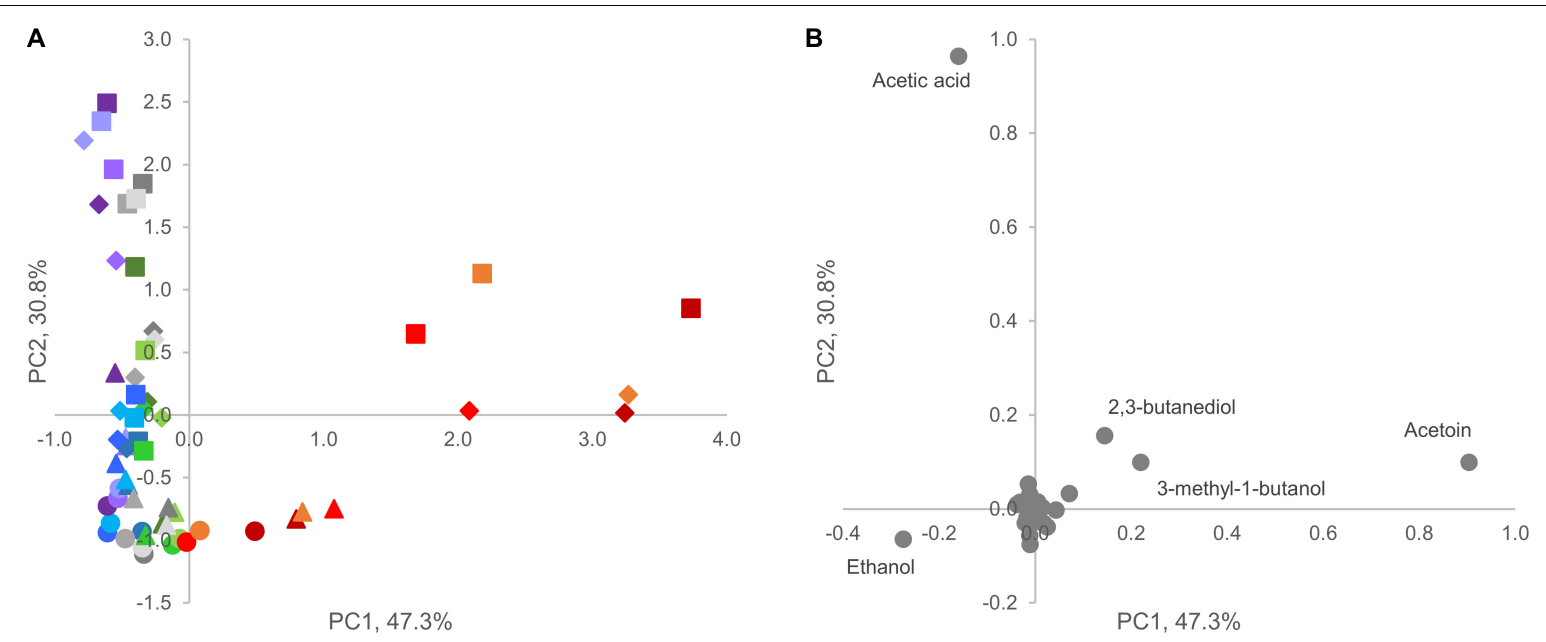

FIGURE 6 | Principal component analysis plot (PC1 vs. PC2) of VOC profiles in A (blue), B (violet), C (green), D (red), and E (gray) samples. (A) Score plot of cooked ham samples; circles, triangles, diamonds, and squares indicate different sampling times ( $0,4,8$, and 12 days, respectively). (B) Loading plot of volatile molecules. Compounds with highest loading value in PC1 vs. PC2 are labeled.

claimed as responsible for greenish color around the cooked ham slices, discoloration, and off-odor, with L. carnosum and L. mesenteroides mainly in charge for sour odor (Björkroth et al., 1998; Leisner et al., 2007; Diez et al., 2008; Schirmer et al., 2009; Comi et al., 2016).

The aroma of cooked ham is characterized by molecules obtained by thermally-induced lipid oxidation, such as straightchain fatty acids, aldehydes, ketones, and alcohols (1-hexanol) (Leroy et al., 2009). The spices added to the product also contributed with terpenoids and sulfides such as 3-carene, gamma-terpinene, humulene, d-limonene, beta-phellandrene, and alpha-pinene (Rux et al., 2019). Moreover, during shelf life, several VOCs were produced from the catabolism of sugars, amino acids, and lipids by the growing microorganisms that dominated the microbiota of the cooked ham during storage (Estévez et al., 2003; Rivas-Cañedo et al., 2009; Holm et al., 2013; Casaburi et al., 2015; Raimondi et al., 2019). Lactic acid, ethanol, acetic acid, acetoin, 3-methyl-1-butanol, and 23 butanediol were the main metabolites that characterized the evolution of the analyzed cooked ham during the secondary shelf life, impacting their sensorial properties. Lactic and acetic acids, together with ethanol, were produced by LAB and other bacteria via saccharolytic metabolism (Casaburi et al., 2015). The increase of acetic acid as a function of sampling time was justified by the widespread presence of heterofermenting bacteria such as $L$. mesenteroides and $L$. carnosum, which dominated the spoilage microbiota of all samples. The lower amount of acetic acid compared with lactic acid was consistent with the results obtained by Vasilopoulos et al. (2008). Other compounds, such as acetoin, 3-methyl-1-butanol, 2-3 butanediol, 3-methylbutanal, 2-butanone, 2-methyl-1-propanol, and 1-hexanol, were produced by LAB and enterobacteria. In particular, the alcohols 2-methyl-1-propanol and 3-methyl-1-butanol derive from the catabolism of amino acids of valine and leucine (Ardö, 2006). The esters were principally produced by enterobacteria and microorganisms able to form esterase involved in the formation of ethyl bonds (Argyri et al., 2015). The increased amount of acetoin in the samples was in good agreement with the complexity of isolated bacteria; in particular, the presence of W. viridescens and L. carnosum was already correlated with acetoin concentration in fermented foods (Diez et al., 2009; Candeliere et al., 2021). In stored sample D, the presence of isolated bacteria ascribable to the genus Candida and in particular C. glaebosa, C. norvegica, and C. zeylanoides was peculiar. The latter was previously described as a highproducing species of acetoin among the non-Saccharomyces yeast (Tofalo et al., 2014).

\section{CONCLUSION}

The main causes of microbial contamination of cooked ham originate from incorrect cooking of meat, improper sanitization practices, and recontamination during slicing and packaging, ensuing the increase of contaminants during the shelf life. Consistently, the analyzed cooked ham presented a more or less rich microbiota already at the opening of packages. Modified atmosphere packaging conditions, usually consisting of $70 \%$ $\mathrm{N}_{2}$ and $30 \% \mathrm{CO}_{2}$, guarantee to some extent the inhibition of chemical and microbial spoilage of the packaged product, thus ensuring a primary shelf life of at least 1 month; the package opening causes a sudden variation of the headspace gas composition and a loss of protection: this event makes so that the secondary shelf life is significantly shorter than primary shelf life. It could be speculated that the problems of microbiological contamination did not derive from conservation during the secondary shelf life but were already present when the packages were opened, 2 weeks before the expiration date of the products, indicating the phases of production up to the packaging as those crucial in managing the safety risk. A high load of LAB already present at the opening of cooked ham packages inhibited the bloom of other species 
and likely prevented the outbreak of pathogenic bacteria. The exploitation of specially selected strains belonging to the genera Latilactobacillus and Leuconostoc with reduced impact on the organoleptic properties of the product could be an effective strategy to control these microbial communities and extend the primary and secondary shelf life of the product, reducing domestic food losses.

\section{DATA AVAILABILITY STATEMENT}

The datasets presented in this study can be found in online repositories. The names of the repository/repositories and accession number(s) can be found below: https://www.ncbi.nlm. nih.gov/, PRJNA778960.

\section{AUTHOR CONTRIBUTIONS}

SR and MR conceived the study. GS and FL carried out chemical analysis. GS and SR carried out the microbiological

\section{REFERENCES}

Abdelradi, F. (2018). Food waste behaviour at the household level: a conceptual framework. Waste Manag. 71, 485-493. doi: 10.1016/j.wasman.2017.10.001

Ahmad, N., Ali, S. M., and Khan, A. U. (2020). Co-existence of blaNDM-1 and blaVIM-1 producing Moellerella wisconsensis in NICU of North Indian Hospital. J. Infect. Dev. Ctries. 14, 228-231. doi: 10.3855/jidc.10969

Ardö, Y. (2006). Flavour formation by amino acid catabolism. Biotechnol. Adv. 24, 238-242. doi: 10.1016/j.biotechadv.2005.11.005

Argyri, A. A., Mallouchos, A., Panagou, E. Z., and Nychas, G. J. (2015). The dynamics of the HS/SPME-GC/MS as a tool to assess the spoilage of minced beef stored under different packaging and temperature conditions. Int. J. Food Microbiol. 193, 51-58. doi: 10.1016/j.ijfoodmicro.2014.09.020

Björkroth, K. J., Vandamme, P., and Korkeala, H. J. (1998). Identification and characterization of Leuconostoc carnosum, associated with production and spoilage of vacuum-packaged, sliced, cooked ham. Appl. Environ. Microbiol. 64, 3313-3319. doi: 10.1128/AEM.64.9.3313-3319.1998

Bolyen, E., Rideout, J. R., Dillon, M. R., Bokulich, N. A., Abnet, C. C., Al-Ghalith, G. A., et al. (2019). Author Correction: reproducible, interactive, scalable and extensible microbiome data science using QIIME 2. Nat. Biotechnol. 37:1091. doi: 10.1038/s41587-019-0252-6

Bonifacie, A., Promeyrat, A., Nassy, G., Gatellier, P., Santé-Lhoutellier, V., and Théron, L. (2021). Chemical reactivity of nitrite and ascorbate in a cured and cooked meat model implication in nitrosation, nitrosylation and oxidation. Food Chem. 348:129073. doi: 10.1016/j.foodchem.2021.129073

Borch, E., Kant-Muermans, M. L., and Blixt, Y. (1996). Bacterial spoilage of meat and cured meat products. Int. J. Food Microbiol. 33, 103-120.

Callahan, B. J. (2016). DADA2: high-resolution sample inference from Illumina amplicon data. Nat. Methods 13, 581-583. doi: 10.1038/nmeth.3869

Candeliere, F., Raimondi, S., Spampinato, G., Tay, M. Y. F., Amaretti, A., Schlundt, J., et al. (2021). Comparative Genomics of Leuconostoc carnosum. Front. Microbiol. 11:605127. doi: 10.3389/fmicb.2020.605127

Casaburi, A., Piombino, P., Nychas, G. J., Villani, F., and Ercolini, D. (2015). Bacterial populations and the volatilome associated to meat spoilage. Food Microbiol. 45, 83-102. doi: 10.1016/j.fm.2014.02.002

Cebrián, E., Núñez, F., Gálvez, F. J., Delgado, J., Bermúdez, E., and Rodríguez, M. (2020). Selection and evaluation of Staphylococcus xylosus as a biocontrol agent against toxigenic moulds in a dry-cured ham model system. Microorganisms 8:793. doi: 10.3390/microorganisms 8060793

Comi, G., Andyanto, D., Manzano, M., and Iacumin, L. (2016). Lactococcus lactis and Latilactobacillus sakei as bio-protective culture to eliminate Leuconostoc mesenteroides spoilage and improve the shelf life and sensorial characteristics of commercial cooked bacon. Food Microbiol. 58, 16-22. doi: 10.1016/j.fm.2016. 03.001 analysis. AA and FC performed the $16 \mathrm{~S}$ rRNA gene profiling, bioinformatics, and statistical analysis. SR wrote the manuscript with contributions from GS, FC, AA, FL, and MR. All authors contributed to the article and approved the submitted version.

\section{FUNDING}

This research was funded by the Italian Ministry of Agricultural, Food, and Forestry Policies (Ministero delle Politiche Agricole, Alimentari e Forestali) through call no. 6146 of November 20, 2019.

\section{SUPPLEMENTARY MATERIAL}

The Supplementary Material for this article can be found online at: https://www.frontiersin.org/articles/10.3389/fmicb. 2022.842390/full\#supplementary-material

Diez, A. M., Björkroth, J., Jaime, I., and Rovira, J. (2009). Microbial, sensory and volatile changes during the anaerobic cold storage of morcilla de Burgos previously inoculated with Weissella viridescens and Leuconostoc mesenteroides. Int. J. Food Microbiol. 131, 168-177. doi: 10.1016/j.ijfoodmicro.2009.02.019

Diez, A. M., Urso, R., Rantsiou, K., Jaime, I., Rovira, J., and Cocolin, L. (2008). Spoilage of blood sausages morcilla de Burgos treated with high hydrostatic pressure. Int. J. Food Microbiol. 123, 246-253. doi: 10.1016/j.ijfoodmicro.2008. 02.017

Drzewiecka, D. (2016). Significance and roles of Proteus spp. bacteria in natural environments. Microb. Ecol. 72, 741-758. doi: 10.1007/s00248-015-0720-6

Dušková, M., Kameník, J., Laèanin, I., Šedo, O., and Zdráhal, Z. (2016). Lactic acid bacteria in cooked hams-Sources of contamination and chances of survival in the product. Food Control 61, 1-5. doi: 10.1016/j.foodcont.2015.09.019

Estévez, M., Morcuende, D., Ventanas, S., and Cava, R. (2003). Analysis of volatiles in meat from Iberian pigs and lean pigs after refrigeration and cooking by using SPME-GCMS. J. Agric. Food Chem. 51, 3429-3435. doi: 10.1021/jf026218h

FAO (2011). Global food losses and food waste - Extent, causes and prevention. Rome: Food and Agriculture Organization of the United Nations.

FAO (2013). Food wastage footprint. Impact on natural resources. Rome: Food and Agriculture Organization of the United Nations.

Hammer, $\varnothing$, Harper, D. A., and Ryan, P. D. (2001). PAST: paleontological statistics software package for education and data analysis. Palaeontol. Electron. 4, 1-9.

Hernández, A., Pérez-Nevado, F., Ruiz-Moyano, S., Serradilla, M. J., Villalobos, M. C., Martín, A., et al. (2018). Spoilage yeasts: what are the sources of contamination of foods and beverages? Int. J. Food Microbiol. 286, 98-110. doi: 10.1016/j.ijfoodmicro.2018.07.031

Holm, E. S., Adamsen, A. P., Feilberg, A., Schäfer, A., Løkke, M. M., and Petersen, M. A. (2013). Quality changes during storage of cooked and sliced meat products measured with PTR-MS and HS-GC-MS. Meat Sci. 95, 302-310. doi: 10.1016/j.meatsci.2013.04.046

Hu, P., Zhou, G., Xu, X., Li, C., and Han, Y. (2009). Characterization of the predominant spoilage bacteria in sliced vacuum-packed cooked ham based on 16S rDNA-DGGE. Food Control 20, 99-104. doi: 10.1016/j.foodcont.2008.02. 007

Iskandar, C. F., Borges, F., Taminiau, B., Daube, G., Zagorec, M., Remenant, B., et al. (2017). Comparative genomic analysis reveals ecological differentiation in the genus Carnobacterium. Front. Microbiol. 8:357. doi: 10.3389/fmicb.2017. 00357

Iulietto, M. F., Sechi, P., Borgogni, E., and Cenci-Goga, B. T. (2015). Meat spoilage: a critical review of a neglected alteration due to ropy slime producing bacteria. Ital. J. Anim. Sci. 14:4011. doi: 10.4081/ijas.2015.4011

Kolbert, C. P., Rys, P. N., Hopkins, M., Lynch, D. T., Germer, J. J., O’Sullivan, C. E., et al. (2004). "16S ribosomal DNA sequence analysis for identification of bacteria in a clinical microbiology laboratory," in Molecular Microbiology: 
diagnostic Principles and Practice, eds D. H. Persing, F. C. Tenover, J. Versalovic, Y. W. Tang, E. R. Unger, D. A. Relman, et al. (Washington, DC: American Society for Microbiology), 361-378.

Kreyenschmidt, J., Hübner, A., Beierle, E., Chonsch, L., Scherer, A., and Petersen, B. (2010). Determination of the shelf life of sliced cooked ham based on the growth of lactic acid bacteria in different steps of the chain. J. Appl. Microbiol. 108, 510-520. doi: 10.1111/j.1365-2672.2009.04451.x

Leisner, J. J., Laursen, B. G., Prévost, H., Drider, D., and Dalgaard, P. (2007). Carnobacterium: positive and negative effects in the environment and in foods. FEMS Microbiol. Rev. 31, 592-613. doi: 10.1111/j.1574-6976.2007.00080.x

Leroy, A. G., Malandain, D., Duchalais, É, Meurette, G., and Corvec, S. (2016). Accurate MALDI-TOF mass spectrometry identification of a colistin-resistant Moellerella wisconsensis strain. Med. Mal. Infect. 46, 233-235. doi: 10.1016/j. medmal.2016.01.009

Leroy, F., Vasilopoulos, C., Van Hemelryck, S., Falony, G., and De Vuyst, L. (2009). Volatile analysis of spoiled, artisan-type, modified-atmospherepackaged cooked ham stored under different temperatures. Food Microbiol. 26:94. doi: 10.1016/j.fm.2008.08.005

Martin, M. (2011). Cutadapt removes adapter sequences from high-throughput sequencing reads. EMBnet J. 17, 10-17. doi: 10.14806/ej.17.1.200

Mekonnen, M. M., and Gerbens-Leenes, W. (2020). The Water Footprint of Global Food Production. Water 12:2696. doi: 10.3390/w12102696

Menezes, N. M. C., Martins, W. F., Longhi, D. A., and de Aragão, G. M. F. (2018). Modeling the effect of oregano essential oil on shelf life extension of vacuumpacked cooked sliced ham. Meat Sci. 139, 113-119. doi: 10.1016/j.meatsci.2018. 01.017

Nicosia, C., Fava, P., Pulvirenti, A., Antonelli, A., and Licciardello, F. (2021). Domestic use simulation and secondary shelf life assessment of industrial Pesto alla genovese. Foods 10:1948. doi: 10.3390/foods10081948

Nielsen, D. S., Jacobsen, T., Jespersen, L., Koch, A. G., and Arneborg, N. (2008). Occurrence and growth of yeasts in processed meat products-Implications for potential spoilage. Meat Sci. 80, 919-926. doi: 10.1016/j.meatsci.2008. 04.011

Ojha, S., Bußler, S., and Schlüter, O. K. (2020). Food waste valorisation and circular economy concepts in insect production and processing. Waste Manag. 118, 600-609. doi: 10.1016/j.wasman.2020.09.010

O’Neill, C. M., Cruz-Romero, M. C., Duffy, G., and Kerry, J. P. (2018). Shelf life extension of vacuum-packed salt reduced frankfurters and cooked ham through the combined application of high pressure processing and organic acids. Food Packag. Shelf Life 17, 120-128. doi: 10.1016/j.fpsl.2018. 06.008

Quartieri, A., Simone, M., Gozzoli, C., Popovic, M., D’Auria, G., Amaretti, A., et al. (2016). Comparison of culture-dependent and independent approaches to characterize fecal bifidobacteria and lactobacilli. Anaerobe 38, 130-137. doi: 10.1016/j.anaerobe.2015.10.006

Raimondi, S., Luciani, R., Sirangelo, T. M., Amaretti, A., Leonardi, A., Ulrici, A., et al. (2019). Microbiota of sliced cooked ham packaged in modified atmosphere throughout the shelf life: microbiota of sliced cooked ham in MAP. Int. J. Food Microbiol. 289, 200-208. doi: 10.1016/j.ijfoodmicro.2018.0 9.017

Raimondi, S., Nappi, M. R., Sirangelo, T. M., Leonardi, A., Amaretti, A., Ulrici, A., et al. (2018). Bacterial community of industrial raw sausage packaged in modified atmosphere throughout the shelf life. Int. J. Food Microbiol. 280, 78-86. doi: 10.1016/j.ijfoodmicro.2018.04.041

Raimondi, S., Spampinato, G., Candeliere, F., Amaretti, A., Brun, P., Castagliuolo, I., et al. (2021). Phenotypic traits and immunomodulatory properties of Leuconostoc carnosum isolated from meat products. Front. Microbiol. 12:730827. doi: 10.3389/fmicb.2021.730827

Rivas-Cañedo, A., Fernández-García, E., and Nuñez, M. (2009). Volatile compounds in fresh meats subjected to high pressure processing: effect of the packaging material. Meat Sci. 81, 321-328. doi: 10.1016/j.meatsci.2008.08.008

Rognes, T., Flouri, T., Nichols, B., Quince, C., and Mahé, F. (2016). VSEARCH: a versatile open source tool for metagenomics. PeerJ. 4:e2584. doi: 10.7717/peerj. 2584

Rux, G., Luca, A., and Mahajan, P. V. (2019). Changes in volatile organic compounds in the headspace of modified atmosphere packed and unpacked white sausages. Food Packag. Shelf Life 19, 167-173. doi: 10.1016/j.fpsl.2018.12. 010
Salihoglu, G., Salihoglu, N. K., Ucaroglu, S., and Banar, M. (2018). Food loss and waste management in Turkey. Bioresour. Technol. 248, 88-99. doi: 10.1016/j. biortech.2017.06.083

Samelis, J., Kakouri, A., and Rementzis, J. (2000). Selective effect of the product type and the packaging conditions on the species of lactic acid bacteria dominating the spoilage microbial association of cooked meats at $4{ }^{\circ} \mathrm{C}$. Food Microbiol. 17, 329-340. doi: 10.1006/fmic.1999.0316

Schirmer, B. C., Heir, E., and Langsrud, S. (2009). Characterization of the bacterial spoilage flora in marinated pork products. J. Appl. Microbiol. 106:2106. doi: 10.1111/j.1365-2672.2009.04183.x

Segata, N., Izard, J., Waldron, L., Gevers, D., Miropolsky, L., Garrett, W. S., et al. (2011). Metagenomic biomarker discovery and explanation. Genome Biol. 12:R60. doi: 10.1186/gb-2011-12-6-r60

Stahnke, L. H. (1994). Aroma components from dried sausages fermented with Staphylococcus xylosus. Meat Sci. 38, 39-53. doi: 10.1016/0309-1740(94)90094-9

Stock, I., Falsen, E., and Wiedemann, B. (2003). Moellerella wisconsensis: identification, natural antibiotic susceptibility and its dependency on the medium applied. Diagn. Microbiol. Infect. Dis. 45, 1-11. doi: 10.1016/s07328893(02)00483-2

Tofalo, R., Fasoli, G., Schirone, M., Perpetuini, G., Pepe, A., Corsetti, A., et al. (2014). The predominance, biodiversity and biotechnological properties of Kluyveromyces marxianus in the production of Pecorino di Farindola cheese. Int. J. Food Microbiol. 187, 41-49. doi: 10.1016/j.ijfoodmicro.2014.06.029

UNEP (2021). Food Waste Index Report 2021. Nairobi: United Nations Environment Programme.

Vasilopoulos, C., De Maere, H., De Mey, E., Paelinck, H., De Vuyst, L., and Leroy, F. (2010). Technology-induced selection towards the spoilage microbiota of artisan-type cooked ham packed under modified atmosphere. Food Microbiol. 27, 77-84. doi: 10.1016/j.fm.2009.08.008

Vasilopoulos, C., De Vuyst, L., and Leroy, F. (2015). Shelf life reduction as an emerging problem in cooked hams underlines the need for improved preservation strategies. Crit. Rev. Food Sci. Nutr. 55, 1425-1443. doi: 10.1080/ 10408398.2012.695413

Vasilopoulos, C., Ravyts, F., De Maere, H., De Mey, E., Paelinck, H., De Vuyst, L., et al. (2008). Evaluation of the spoilage lactic acid bacteria in modifiedatmosphere-packaged artisan-type cooked ham using culture-dependent and culture-independent approaches. J. Appl. Microbiol. 104, 1341-1353. doi: 10. 1111/j.1365-2672.2007.03664.x

White, T. J., Bruns, T., Lee, S., and Taylor, J. W. (1990). "Amplification and direct sequencing of fungal ribosomal RNA genes for phylogenetics," in PCR Protocols: a Guide to Methods and Applications, eds M. A. Innis, D. H. Gelfand, J. J. Sninsky, and T. J. White (New York, NY: Academic Press), 315-322. doi: 10.1016/b978-0-12-372180-8.50042-1

Wohner, B., Pauer, E., Heinrich, V., and Tacker, M. (2019). Packaging-Related Food Losses and Waste: an Overview of Drivers and Issues. Sustainability 11:264. doi: 10.3390/su11010264

Zagdoun, M., Coeuret, G., N’Dione, M., Champomier-Vergès, M. C., and Chaillou, S. (2020). Large microbiota survey reveals how the microbial ecology of cooked ham is shaped by different processing steps. Food Microbiol. 91:103547. doi: 10.1016/j.fm.2020.103547

Conflict of Interest: The authors declare that the research was conducted in the absence of any commercial or financial relationships that could be construed as a potential conflict of interest.

Publisher's Note: All claims expressed in this article are solely those of the authors and do not necessarily represent those of their affiliated organizations, or those of the publisher, the editors and the reviewers. Any product that may be evaluated in this article, or claim that may be made by its manufacturer, is not guaranteed or endorsed by the publisher.

Copyright (C) 2022 Spampinato, Candeliere, Amaretti, Licciardello, Rossi and Raimondi. This is an open-access article distributed under the terms of the Creative Commons Attribution License (CC BY). The use, distribution or reproduction in other forums is permitted, provided the original author(s) and the copyright owner(s) are credited and that the original publication in this journal is cited, in accordance with accepted academic practice. No use, distribution or reproduction is permitted which does not comply with these terms. 